Scientiæ studia, São Paulo, v. 12, n. 3, p. 607-18, 2014

$$
\begin{array}{r}
\text { A produção dos dados pela grande máquina: } \\
\text { computadores, modelagem e sistemas técnicos } \\
\text { nas ciências do clima } \\
\text { José Gorrea Leite }
\end{array}
$$

\title{
A vast machine: computer models, climate data, and the politics of global warming
}

Paul N. Edwards

The MIT Press

Cambridge (MA), 2010, $55^{2}$ págs.

Paul Edwards é professor da Escola de Informação e do Departamento de História da Universidade de Michigan. Seu primeiro livro, The closed world: computers and the politics of discourse in cold war America, de 1996, acompanhava o desenvolvimento dos computadores nos Estados Unidos e sua imbricação com o discurso da Guerra Fria. O computador contribuiu para criar a ilusão de que o país era impenetrável, defendido por um sistema automático, donde a metáfora do "mundo fechado". Os computadores foram, nos Estados Unidos, a tecnologia central das forças militares na Guerra Fria, mas também a metáfora estruturante da teoria psicológica que se desenvolveu nesse período com as ciências cognitivas e as pesquisas de inteligência artificial. The closed world mostra essa trajetória dual nos Estados Unidos durante a Guerra Fria.

A vast machine: computer models, climate data, and the politics of global warming, último livro de Edwards, se insere na trajetória aberta por seu primeiro livro, elaborando agora uma "narrativa histórica da ciência do clima como uma infraestrutura global de conhecimento" (p. 8), um empreendimento já antigo, mas no qual os computadores se transformaram na peça-chave. Trata-se de uma epistemologia das ciências do clima, uma defesa da legitimidade dos modelos de computador como ferramentas de apreensão da dinâmica desses fenômenos. Tem, todavia, um alcance que ultrapassa $o$ âmbito das ciências do clima, aplicando-se para muitas das ciências do sistema Terra.

A obra mostra como o conhecimento do clima tornou-se, desde o século xIx, indissociável dessa "grande máquina", fórmula que dá título à obra, através da qual Edwards retoma uma ideia lançada na Inglaterra vitoriana por John Ruskin a propósito da Sociedade Meteorológica, cuja influência e poder deveriam ser onipresentes no pla- 
neta. O desenvolvimento dessa infraestrutura global de conhecimento é resultado dos avanços nos sistemas nacionais de previsão do tempo, baseados no telégrafo, que se dotaram de uma coordenação internacional frouxa, avançando no século xx com o uso de computadores, depois satélites, até a criação do Observatório Mundial do Tempo.

\section{A simbiose DAdos-Modelos}

O ponto central da análise de Edwards é a crítica da separação entre modelos e dados e a defesa da simbiose entre eles. Céticos do clima e negacionistas desqualificam as análises sobre o aquecimento global antropogênico afirmando que seus defensores apresentam apenas modelos e o que importa são os dados. Mas Edwards enfatiza que sem modelos, não há dados globais. Dados globais, aqueles com que trabalha a climatologia, são produzidos pelos pesquisadores a partir de fontes diversas. "Nenhuma coleção de sinais ou observações - mesmo de satélites, que podem "ver" todo o planeta - torna-se global no espaço e no tempo sem primeiro passar por uma série de modelos de dados" (p. xıII). E como tanto os sistemas de observação do clima que fornecem registros como os modelos de tratamento dos dados evoluem, os dados globais também mudam, existindo a partir daí diversas visões do passado climático da Terra, com dados reverberando permanentemente no que o autor chama de cintilações. É a convergência das imagens oferecidas por essas diferentes séries de dados globais construídas por distintos modelos que permite afirmar que a Terra aqueceu o, $75^{\circ}$ desde 1900. Há simulações, mas esses modelos são distintos dos modelos de tratamento de dados que tornam os registros dos diversos instrumentos operacionais. "Tudo o que nós conhecemos sobre o clima do mundo - passado, presente e futuro - conhecemos através de modelos" (p. xIV).

Pode-se estudar a história do clima de duas maneiras: coletando dados do passado, colhidos pelas leituras de instrumentos que começaram a existir no século xvı, se tornaram comuns depois de $185^{\circ}$ e avançaram acima da superfície da Terra depois de $195^{\circ}$ (o que Edwards chama de produção de dados globais), e compreendendo o clima como um sistema físico, o que pode permitir prever sua mudança (uma tarefa enorme e complexa, que envolve muitos sistemas interligados: atmosfera, oceanos, criosfera, superfícies com diferentes solos e albedos e a biosfera com seus ecossistemas e territórios agrícolas). Assim, o que conhecemos do clima advém dos três tipos de modelos de computador estudados por Edwards: os modelos de simulação baseados na física teórica, com simulações numéricas tanto para a meteorologia (a previsão do tempo, em geral modelos regionais ou continentais) como para a climatologia (modelos para longo prazo, anos ou décadas, incorporando mudanças na composição e 
forçantes da atmosfera); os modelos de análise de dados (resumidamente, os modelos de dados), compreendendo uma grande quantidade de técnicas matemáticas, algoritmos e ajustes derivados das leituras de instrumentos, ambas em constante evolução; e os modelos de reanálise das previsões do tempo, simulações baseadas nas observações reais do tempo passado, que passaram a criar, depois de 1990, uma nova fonte de dados globais do clima.

A climatologia passou a necessitar de muito mais informações do que as providas pela meteorologia. Isso levou a um trabalhoso processo de reanálise dos dados a partir da década de 1970, que Edwards chama de inversão infraestrutural. Desde então, a modelagem climática ultrapassou o conhecimento de base empírica como fundamento da ciência do clima. Com a preocupação com o aquecimento global a partir dos anos 1980, cientistas e governos institucionalizaram um processo de revisão sistemática do conhecimento sobre o clima no Painel Intergovernamental sobre Mudanças Climáticas (IPCG em inglês), hoje a camada mais visível da vasta e complexa infraestrutura de produção de conhecimento da climatologia. Esse processo de revisão, que teve cinco rodadas desde 1990, criou imperativos, estruturas e processos articulando um vasto leque de produtores de conhecimento e trazendo para um projeto comum métodos e produtos os mais diversos. As controvérsias são levadas para dentro do consenso científico, que incorpora o leque de opiniões dos especialistas. E é dentro desse processo que inúmeras versões da história recente da atmosfera - provenientes de diferentes modelos - também convergiram.

\section{Pensando globalmente}

Para Edwards, a apreensão da Terra como um todo constitui uma "quarta descontinuidade”, um deslocamento fundamental de perspectiva como aqueles trazidos por Copérnico, Darwin e Freud, uma nova visão do mundo sintetizada na máxima "pensar globalmente, agir localmente", que "captura toda uma filosofia, com ontologia, epistemologia e ética" (p. 1). O planeta passa a ser visto como um sistema dinâmico, interconectado, articulado e em mudança, mas frágil: uma "rede, ao invés de hierarquia; complexa, com retroalimentações cruzadas, ao invés de controle central; [com] ecologia, ao invés de recursos" (p. 2). Embora a fotografia da Terra tirada da órbita lunar pelos astronautas da Apolo 8 em 1968 possa ser o melhor símbolo da ideia de uma Terra global, essa noção começou a emergir antes, durante a década de 1950, já estando presente no Ano Geofísico Internacional de $1957^{-5} 5^{8}$, nos primeiros satélites, na cibernética, na ecologia etc. $\mathrm{O}$ mundo estava se tornando um sistema. 
Como isso se deu? A resposta que Edwards oferece a essa questão, através da discussão do aquecimento global, é que na medida em que vai se constituindo uma infraestrutura global de conhecimento (de monitoramento, modelagem e memória) isso produz um conhecimento integrado e a necessidade de políticas globais. Isso surge no estudo do tempo e do clima no século xIx, avançando até o presente, em um processo que é repetido em outras disciplinas que vão se interconectando, partilhando dados e marcos teóricos. Se o mundo é um sistema, seu conhecimento terá que se dar por outro sistema.

O "globalismo infraestrutural" é marcado pela proeminência das tecnologias da informação e da comunicação. Edwards recolhe de Hewson o conceito de "globalismo informacional", que se refere aos sistemas e instituições para criar e para transmitir informações por todo o mundo, um globalismo que emerge com as redes de telégrafos. Eles se articularam, no capitalismo liberal do século xIx, em redes inter-regionais e intercontinentais, refluindo entre 1914, e 1960 e ganhando ímpeto desde então. Para o autor, "o imperativo informacional globalista era já muito mais forte [nos anos 1950] na meteorologia do que em muitos outros supostos sistemas 'globais' que emergiram naquele período" (p. 24) - como de outras ciências geofísicas (sismologia, oceanografia etc.), da epidemiologia das doenças infecciosas ou dos mercados financeiros. O globalismo infraestrutural foi um projeto que, ao criar uma vasta infraestrutura, "perdura muito além das carreiras individuais, dos movimentos sociais ou das tendências políticas. Essa permanência legitima, ela própria, o conhecimento que produz e se torna autoperpetuadora" (p. 25).

\section{A PREVISÃo METEOROLÓGIGA}

$A$ vast machine trata, nos capítulos 2 a 5 , da história da previsão do tempo e da climatologia até a Segunda Guerra. Tais capítulos são uma síntese da produção acadêmica sobre a história dessas disciplinas, apoiando-se no trabalho dos principais autores da área (cf. Harper, 2008; Nebeker, 1995; Weart, 2008), e não vamos aqui poder fazer jus a eles com a riqueza de detalhes que merecem. Em "Espaço global, tempo universal: vendo a atmosfera planetária", Edwards nos lembra que hoje mapas do mundo estão por todas as partes e são objetos com os quais pensamos inúmeros problemas, inclusive a ideia de um espaço global. Eles são o principal suporte material para "pensarmos globalmente". Da mesma forma, o tempo universal é fundamental para a textura da vida moderna. A sincronização dos tempos locais se torna viável com o telégrafo e necessária com as ferrovias. Essas são condições para visualizarmos a atmosfera em movimento. 
A representação gráfica do tempo não existia ante de Humboldt publicar, em 1817, a primeira representação de "isotérmicas", demarcando zonas de temperatura média similar. Dove produz, em 1852, o primeiro mapa isotérmico da Terra, utilizando o método de Humboldt para descobrir a relação entre a pressão atmosférica e a direção do vento durante a passagem de tempestades. A utilização das isolinhas agudizou a consciência da precariedade dos dados existentes. Até meados do século xix nenhuma rede meteorológica tinha durado mais do que vinte anos. Mas havia uma "comunalidade de dados", com seu compartilhamento entre os estudiosos do tempo e do clima, o que ajudou a transformar a meteorologia em uma ciência aberta e cosmopolita.

A meteorologia tornou-se uma infraestrutura cumulativa, preservando o máximo de informações onde elas poderiam ser armazenadas, analisadas, sistematizadas e distribuídas em grandes bancos de dados. Maury, por exemplo, coletou diários de navios registrando ventos e correntes marinhas, publicando mais de 200 volumes de informações. E também organizou, em 1853, a primeira conferência intergovernamental para tratar da padronização dos sistemas de observação. Esse trabalho permitiu a William Ferrel descobrir o esquema de três células globais de distribuição da circulação atmosférica, comprovado um século depois com o auxílio de sondas, aviões e satélites.

As transformações ocorridas entre 1840 e 1890 produziram uma aceleração das velocidades: temos, pela primeira vez, a circulação de informações em tempo real. Isso revolucionou a meteorologia, que podia agora reunir grandes quantidades de informações em mapas "sinópticos". Juntando as informações de temperatura e pressão às da direção e velocidade do vento era possível dizer como o tempo estava se movendo, fornecendo uma base racional para a previsão do tempo. Um primeiro sistema europeu de aviso de tempestades surgiu em 1860. Nos Estados Unidos, um serviço federal de meteorologia foi votado em 1870, tornando-se, em 1891, o Escritório do Tempo.

Muitos processos pressionavam no sentido de uma padronização do tempo, como já destacou Peter Galison (2003). Na Inglaterra, o sistema ferroviário adotou o horário do meridiano de Greenwich para suas operações em 1847. Para a meteorologia era necessário adotar a observação sincronizada do tempo segundo a mesma hora universal. Em 1883, os EUA adotaram o mesmo sistema padrão de zonas de hora, com Greenwich como primeiro meridiano.

\section{A primeira Glimatologia}

Embora a estrutura geral da atmosfera tenha sido estabelecida em meados do século XIX, a relação geral entre a circulação e o clima permaneceu pouco compreendida. A climatologia era, antes de 1914, dominada por abordagens qualitativas e estudos regionais. 
Edwards recupera a análise de Nebeker (1995) mostrando a divisão da meteorologia, no século xıx, em três campos distintos, cada um com uma relação diferente com os dados numéricos. Aqueles voltados para a previsão do tempo desenvolveram métodos que não problematizavam as causas que não afetavam as previsões, priorizando as cartas sinópticas e as isolinhas como técnicas de visualização e valorizando a experiência prática dos meteorologistas. Os físicos aplicados ou meteorologistas teóricos abordavam o tempo dedutivamente, através da física teórica (dinâmica dos fluidos, física dos gases etc.). Aqui também a quantificação permanecia pouco importante porque não existiam métodos numéricos para dar conta do movimento da atmosfera. O terceiro campo era o dos empiristas, que consideravam a atmosfera um sistema muito complexo, que deveria ser abordado dedutivamente, a partir da análise das observações e não dos fundamentos da mecânica do movimento, calor e comportamento dos gases. É desse campo que Edwards vê emergir, através do uso de métodos estatísticos, na virada para o século xx, uma climatologia ligada não à meteorologia, mas à geografia.

Na sequência, Edwards retoma a descrição feita por Spencer Weart em The discovery of global warming para mostrar como o problema das mudanças climáticas vinha sendo estudado com sucesso, no século xIx, pelos meteorologistas teóricos a partir da física e da química. A geologia tinha estabelecido que a Terra era muito antiga e havia passado tanto por diversas eras glaciais, como conhecido climas muito quentes. Fourier, Tyndall e Arrhenius assentaram gradativamente, ao longo do século xıx, as bases para o estudo do efeito estufa, seu impacto na definição do clima e o papel central do dióxido de carbono nisso. Mas entre 1900 e 1905, Angstrom e outros concluíram (incorretamente, descobriu-se depois) que o efeito do vapor d'água sobre a temperatura da Terra seria muito superior ao do $\mathrm{CO}_{2}$. A teoria do dióxido de carbono desapareceu da climatologia até o final dos anos 1930 para reemergir com as pesquisas de Guy Callendar, que apontou de maneira mais precisa seu impacto sobre o clima global.

Mas os climatologistas permaneceram céticos em relação ao trabalho de Callendar. A razão para isso foi, segundo Edwards, a fricção de dados, conceito que ele utiliza para descrever o trabalho necessário para converter os dados em informações úteis. Estamos acostumados a naturalizar a atual capacidade de computação, não levando em conta que ela é muito recente. Antes, computadores eram enormes máquinas frágeis que consumiam vasta quantidade de energia e eram alimentados por cartões perfurados. Antes ainda, computadores eram pessoas com lápis e máquinas simples. "Cada cálculo requer tempo, energia e atenção humana. Esses gastos de energia e recursos limitados no processamento de números pode ser chamado de fricção computacional" (p. 83), por analogia à resistência dos sistemas físicos. "Sistemas de informação transformam dados (entre outras coisas) em informação e conhecimento. A fricção computacional se opõe a essa transformação; ela expressa a resistência que 
A produção dos dados Pela grande máquina...

deve ser superada, a luta sociotécnica com os números que sempre precede a recompensa. A fricção computacional reduz a quantidade de informação e conhecimento que pode ser extraída de um dado insumo" (p. 83).

\section{O ADVENTO DA PREVISÃO POR GÁLGULO NUMÉRIGO}

Desde que Vilhelm Bjerknes mostrou que os grandes sistemas de tempo podiam ser descritos por equações de movimento e estado abriu-se a possibilidade da previsão numérica do tempo. Bjerknes criou uma teoria do tempo a partir das leis da dinâmica de fluidos, descrevendo o tempo a partir de sete variáveis: pressão, temperatura, densidade, umidade e as três dimensões do movimento. Dado um estado inicial, essas equações permitiam a sua previsão, não a partir de uma experiência subjetiva analisando mapas sinópticos, mas a partir do cálculo objetivo baseado em leis físicas. Mas, há um século, resolver essas equações era extremamente difícil, dados os métodos matemáticos disponíveis. Bjerknes dirigiu sua atenção, então, para a meteorologia prática, estabelecendo o que é conhecido como Escola de Bergen.

A Primeira Guerra transformou a meteorologia em uma atividade militar importante. Assimilando a experiência prática adquirida na Alemanha, Bjerknes e seus colaboradores redefiniram os conceitos básicos de previsão do tempo. A Escola de Bergen visualizava o tempo como a colisão entre massas descontínuas de ar. Tempestades ocorriam quando duas frentes de massas colidiam; entre 1919 e 1920, a Escola desenvolveu a noção de frente polar. Sua abordagem tridimensional tornou-se particularmente útil com o desenvolvimento da aviação comercial. A Escola de Bergen tinha impulsionado a previsão do tempo com técnicas e conceitos descritivos e não teóricos, uma ironia para o cientista que tinha demonstrado a possibilidade da previsão matemática do tempo.

A Segunda Guerra deu novamente centralidade à meteorologia e, ao final dos combates, até mesmo o controle do tempo passou a ser concebido como uma possível arma, caso se conseguisse manejar os cálculos numéricos (hoje sabemos que isso é ilusório, mas depois da primeira bomba atômica tudo parecia possível aos militares e cientistas norte-americanos). John von Neuman, um dos maiores matemáticos do século xx e um falcão da Guerra Fria, concebeu o uso dos primeiros computadores para esse trabalho. Com respaldo militar e incorporando também o sueco Carl-Gustav Rossby, Neuman usou seu prestígio para impulsionar o Projeto Meteorológico, uma iniciativa que integrava o desenvolvimento do computador digital segundo a arquitetura projetada por ele e a resolução dos problemas matemáticos ainda pendentes para a previsão do tempo. Inicialmente avançando lentamente, o Projeto ganhou impulso 
quando Jule Charney tomou a frente da parte matemático-meteorológica da iniciativa, em 1948. O projeto tornou-se operacional em 1952: com o novo computador, uma previsão de 24 horas exigia duas horas e meia de tempo de trabalho a toda velocidade. A previsão por cálculo numérico tornou-se operacional nos EUA em maio de 1955 e acurada em 1958. Iniciou-se, então, uma nova etapa da meteorologia, envolvendo novos avanços na teoria e nos métodos matemáticos, mas principalmente uma demanda sempre crescente de capacidade de computação. Dobrar a resolução de uma grade meteorológica tridimensional significava multiplicar por oito o volume de dados processados, um enorme problema para os computadores de então.

Edwards observa que os serviços de meteorologia empenharam-se em uma corrida pela previsão numérica do tempo com computadores porque as velhas técnicas tinham chegado a seu limite, porque representavam uma transição geracional para uma meteorologia cientificamente mais sofisticada e porque Charney, Rossby e von Neuman articularam um programa de pesquisa e desenvolvimento claro para a previsão numérica do tempo. Além disso, os militares ofereciam apoio político e financeiro ao projeto. Os computadores ainda levariam muitos anos para se tornarem comercialmente viáveis. Mas as promessas eram altas - incluindo a inteligência artificial-e seguravam os projetos mesmo quando fracassavam. Em meados dos anos 1960, os computadores tinham propiciado a reunificação da previsão do tempo com a meteorologia teórica.

\section{Os MOdelos DE GIRGULAÇÃo Geral}

O capítulo "A previsão infinita" trata do impacto do computador na climatologia. Essa transição não foi liderada pelos climatologistas mas pelos cientistas trabalhando com a meteorologia teórica e a programação de computadores. Esses novos climatologistas não buscavam regularidades estatísticas no clima, mas simular o clima com modelos semelhantes aos utilizados na previsão numérica do tempo. Eles moveram-se gradualmente em direção a simular o sistema Terra como um todo, replicando o mundo em uma máquina.

As consequências eram enormes. "Se você pode simular o clima, você pode fazer experimentos. Como Deus, você pode mover continentes, fazer o Sol brilhar ou empalidecer, adicionar ou subtrair gases do efeito estufa ou encher a estratosfera com poeira. Você pode cozinhar a Terra ou congelá-la e ninguém reclamará. Então você pode observar e ver o que acontece" (p. 139). Como os sistemas são muito complexos, você isola e manipula as variáveis consideradas mais importantes. Mas não há nenhum controle - exceto um ocasional experimento natural, como uma erupção vulcânica capaz de afetar todo o planeta por um ano ou dois. John von Neuman, que veio do Projeto 
Manhattan, foi um dos poucos que compreenderam o que significava você poder manipular os procedimentos computacionalmente.

Tornou-se, então, possível formular modelos de circulação atmosférica global ou geral (MCG), que representavam o último degrau do programa de pesquisa meteorológica de von Neuman, possibilitando o que ele chamava de previsão infinita. Esses modelos permitiam reunificar as três dimensões da meteorologia separadas no século XIX - previsão do tempo, teoria e climatologia empírico-estatística. Edwards descreve sucessivos modelos de circulação geral produzidos depois dos anos 1950, destacando aqueles que estiveram na origem, depois, de dezenas de outros. Além disso, o desenvolvimento de um MCG pressupunha acesso a supercomputadores, algo inicialmente caro e difícil, e era condicionado pela capacidade de processamento das máquinas, que cresceu exponencialmente. Se o IBM 701, utilizado em 1956-57, tinha uma performance relativa de 1, em 1974 o Texas X4ASC tinha uma performance de três mil. E entre $197^{8}$ e 2006 esse avanço foi de 90 mil vezes. A difusão de supercomputadores permitiu a multiplicação dos centros de climatologia que podiam construir seus próprios modelos; nos anos 1990, 33 grupos apresentaram seus MCGs para um projeto de comparação entre eles. A climatologia se tornou uma das grandes usuárias de supercomputadores do mundo, atrás apenas do desenvolvimento de armas nucleares e da física de partículas.

\section{Dados Globais, GLObalizaçÃo dos DAdos E GUERRA DE DADos}

Os capítulos 8 a 12 de $A$ vast machine reconstituem o desenvolvimento da infraestrutura informacional sobre o tempo e o clima: como os dados do clima global são coletados (making global data) e como eles são analisados e modelados para serem utilizados pelos climatologistas (making data global). Nos anos 1950, os cientistas trabalhando com MCG perceberam que não tinham dados suficientes, "pelo menos não nos formatos corretos (padronizados e processáveis por computador), dos lugares certos (de grades uniformes em diferentes alturas) e das horas certas (observações tomadas simultaneamente ao redor do globo). O computador... agora também se tornou uma ferramenta para refinar, corrigir e moldar dados para responder às necessidades dos modelos. Enquanto isso, os modelos começaram a moldar as estratégias de aquisição de dados" (p. 187). Isso incluía, por vezes, desenvolver modelos intermediários capazes de criar dados para áreas do mundo onde não existiam observações. "Virtualmente tudo o que nós hoje chamamos de 'dados globais' não foi simplesmente coletado; foi checado, filtrado, interpretado e integrado por modelos computacionais" (p. 188). 
Os imperativos geopolíticos da Guerra Fria interferiam na circulação de dados sobre o tempo e o clima, cuja estrutura era, nos anos 1950, por quase toda parte, militar. Além disso, os testes atmosféricos de armas nucleares também demandavam previsões acuradas do tempo e dos movimentos das nuvens de poeira radioativa. E o monitoramento deveria ajudar a detectar explosões nucleares a distância e a avaliar a precipitação radioativa, o que estimulou progressos no estudo do ciclo do carbono e das mudanças climáticas, e resultou, por exemplo, na quantificação anual do aumento da quantidade de $\mathrm{CO}_{2}$ na atmosfera (de 315 partes por milhão em 1957 para mais de 4, oo ppm hoje).

O resultado desse processo conflitivo e colaborativo foi o Observatório Mundial do Tempo da Organização Meteorológica Mundial, a primeira estratégia global de trabalho entre redes. $\mathrm{O}$ globalismo infraestrutural foi bem sucedido porque adotou uma estratégia flexível, capaz de impulsionar a convergência de interesses das agências nacionais. Nessa etapa, a "era dos satélites" já trazia novos problemas. Com a utilização cotidiana de dados coletados por sensoriamento remoto, que suprem a falta de dados onde não existem estações meteorológicas terrestres ou em altas altitudes, a climatologia passou a trabalhar com quantidades colossais de dados ainda mais heterogêneos.

A ciência tinha agora que tornar os dados globais, construindo conjuntos de dados completos, coerentes e consistentes a partir de fontes incompletas, inconsistentes e heterogêneas. Produzir dados globais envolve padronizar a coleta e a comunicação dos dados, algo essencial para reduzir a fricção dos dados pela redução da sua variação e da complexidade. Não existem, pois, os dados brutos sobre o clima que reclamam os negacionistas. "Se você quer dados globais, você tem que produzi-los. Você faz isso invertendo a infraestrutura, recuperando metadados e usando modelos e algoritmos para misturar e suavizar dados diversos e heterogêneos que são distribuídos de forma desigual no espaço e no tempo" (p. 321).

\section{Os modelos E A POLÍtiGa do GLIMA}

Os dois capítulos finais tratam da relação entre modelos, dados e a política atmosférica. O autor evidencia como o aquecimento global tornou-se um problema político. Nos anos 1980, emergiam, sob o governo Reagan e seu projeto Guerra nas Estrelas, a questão do "inverno nuclear", da política para fazer frente ao buraco na camada de ozônio e, após a Conferência de Villach, na Áustria, em 1985, do aquecimento global, que não abandonou mais o terreno da política global. "Juntos e separadamente, essas preocupações manifestaram o tema de que a atividade humana podia afetar a atmosfera da Terra não apenas local e regionalmente - como 'poluição' - mas em uma escala plane- 
tária. Em 1992, o aquecimento global tinha aterrissado na Conferência das Nações Unidas sobre o Ambiente e o Desenvolvimento, que culminou na Convenção-Quadro das Nações Unidas sobre Mudança Climática" (p. 358). O autor mostra como, ao longo dessas controvérsias, a modelagem se estabelece como uma fonte legítima de conhecimento relevante para orientar a ação política. E conclui que a ciência do clima afirmou-se na política, nos anos 1980, quando os cientistas começaram a estabilizar um conjunto de modelos preditivos ligados principalmente ao aquecimento global. "Consideradas heurísticas, essas figuras, princípios e tendências permaneceram essencialmente as mesmas desde então" (p. 359).

O capítulo final tem como foco o IPCG e a forma como vem se dando o debate sobre o clima desde 1990. O IPGG é uma instituição verdadeiramente global, uma agência intergovernamental sob os auspícios da ONU, conduzida quase que inteiramente por cientistas. Sua tarefa é rever periodicamente o conhecimento produzido na área, envolvendo milhares de colaborares na tarefa e publicando suas conclusões. Conforme críticas são feitas, sua metodologia de trabalho é alterada para reforçar a legitimidade de seus resultados. A análise das controvérsias climáticas descrita por Edwards mostra como as polêmicas públicas e o monitoramento de uma blogosfera crítica terminam por reforçar o processo de ciência, ao trazerem a controvérsia para dentro do consenso. A transparência em um processo tão amplo e sólido como o do IPCG, respaldado não em uma disciplina, mas em um conjunto delas, cada uma com seus próprios métodos, acaba sendo útil para eliminar vieses e fortalecer a pesquisa para além da comunidade científica. Isso permite que um setor amplo da sociedade respalde a atividade científica não como produtora de verdades absolutas, mas do melhor conhecimento possível, com todas as incertezas e conclusões provisórias que lhe são inerentes.

É nesse sentido que Edwards conclui o livro questionando uma corrente contemporânea dos estudos de ciência e tecnologia que, tendo afirmado corretamente o caráter social da construção do conhecimento, mergulha em um relativismo radical, restringindo a ciência a uma forma de conhecimento entre as demais e colocando uma suspeita corrosiva sobre todo o conhecimento por ela produzido. É importante reconhecer o caráter provisório desse conhecimento, mas também reconhecer que a ciência é capaz de incorporar a controvérsia no processo de construção de consensos. É o melhor conhecimento que somos capazes de obter.

O livro de Paul Edwards é uma referência obrigatória para a epistemologia da ciência do clima. Seus méritos ficam evidentes. Mas não podemos concluir estes comentários sem pontuar uma lacuna importante, inclusive porque é central para os problemas que o autor trata: o estudo de Edwards não abarca as reconstruções do clima passado a partir da paleoclimatologia, uma área das ciências do clima em grande ex- 
pansão nas décadas recentes, embora muitos elementos de sua argumentação sobre os modelos também possam ser estendidos para ela. Mas isso não empalidece o brilho da obra de Edwards e sua contribuição para o entendimento de uma das fronteiras da ciência contemporânea.

Agradecimentos. A resenha aqui publicada faz parte da pesquisa viabilizada pela bolsa de pós-doutorado da Fapesp junto ao Projeto Temático $(2011 / 51614-3)$ "Gênese e significado da tecnociência: das relações entre ciência, tecnologia e sociedade".

José Correa Leite

Faculdade de Comunicação, Fundação Armando Álvares Penteado, São Paulo, Brasil. jcleite@dglnet.com.br

Data production by a vast machine: computers, modeling and technical systems in climate sciences

\section{REFERÊNGIAS BIBLIOGRÁFIGAS}

EDwards, P. N. The closed world: computers and the politics of discourse in cold war America. Cambridge: The MIT Press, 1996.

. A vast machine: computers models, climate data, and the politics of global warning. Cambridge: The MIT Press, 2010.

Galison, P. Einstein's clock, Poincaré's maps. Empires of time. Norton: New York, 2003.

HARPER, K. Weather by the numbers: the genesis of modern meteorology. Cambridge: The MIT Press, 2008. Nebeker, F. Calculating the weather. Meteorology in the zoth century. San Diego: Academic Press, 1995.

Weart, S. The discovery of global warming. Cambridge: Harvard University Press, 2008. 